\title{
PERAN SARANA PELAYANAN KESEHATAN TERHADAP KEJADIAN MALARIA DI KECAMATAN SILIAN RAYA KABUPATEN MINAHASA TENGGARA
}

\author{
${ }^{1}$ Meilany Tangkilisan \\ ${ }^{2}$ Angle Sorisi \\ ${ }^{2}$ Josef S. B. Tuda
}

\author{
${ }^{1}$ Kandidat Skripsi Bagian Fisika Kedokteran Universitas Sam Ratulangi Manado \\ ${ }^{2}$ Bagian Parasitologi KlinikFakultas Kedokteran Universitas Sam Ratulangi Manado \\ Email : mtangkilisan_11_174@yahoo.com
}

\begin{abstract}
The problem of public health, especially in developing coutries such as Indonesia, is based on the physical aspects such as health facilities, the treatment of disease, and non physical aspects related to the health problem. Malaria is still a public health problem because it often creates exrtraordinary events, which has great impact on quality on life and economy, and may result death. The main keys of reducing the incidence of malaria especially in high endemic areas are prevention and treatment. This study aimed to determine the role of health care facilities on the incidence of malaria in Silian Raya sub-district of Southheast Minahasa district. This was a descriptive survey study. The population was the community in Silian Raya sub-district of Southeast Minahasa district with total samples 194 respondents. The results showed that the counseling done by health workers was at the most 2 times (39.2\%). Spraying insecticide by health workers was 1 time (41.8\%). People that used the available health care facilities in Silian Raya sub-district, the health center, were 51.0\%.
\end{abstract}

Keywords: malaria, prevention, treatment

\begin{abstract}
Abstrak: Masalah kesehatan masyarakat terutama di negara-negara berkembang seperti Indonesia didasarkan pada, aspek fisik seperti sarana kesehatan dan pengobatan penyakit, dan aspek non fisik yang menyangkut masalah kesehatan.Malaria masih merupakan masalah kesehatan masyarakat karena sering menimbulkan Kejadian Luar Biasa (KLB), berdampak luas terhadap kualitas hidup dan ekonomi, serta dapat mengakibatkan kematian. Dalam upaya mengurangi angka kejadian malaria terutama di daerah endemis tinggi, upaya pencegahan dan pengobatan merupakan kunci utama. Tujuan penelitian ini untuk mengetahui peran sarana pelayanan kesehatan terhadap kejadian malaria di Kecamatan Silian Raya Kabupaten Minahasa Tenggara. Jenis penelitian ini adalah survey yang bersifat deskriptif. Populasi penelitian adalah masyarakat di Kecamatan Silian Raya Kabupaten Minahasa Tenggara dengan jumlah sampel 194 responden. Hasil penelitian menunjukkan penyuluhan yang dilakukan oleh tenaga kesehatan tertinggi 2 kali (39,2\%). Penyemprotan insektisida oleh tenaga kesehatan tertinggi 1 kali $(41,8 \%)$ dan masyarakat yang langsung memanfaatkan sarana pelayanan kesehatan yang tersedia di Kecamatan Silian Raya yaitu Puskesmas (51,0\%).
\end{abstract}

Kata kunci: malaria, pencegahan, pengobatan

Masalah kesehatan masyarakat terutama di negara-negara berkembang seperti Indonesia didasarkan pada dua aspek utama yaitu, aspek fisik seperti sarana kesehatan dan pengobatan penyakit, sedangkan yang kedua adalah aspek non fisik yang menyangkut masalah kesehatan. ${ }^{1}$ Malaria masih merupakan masalah kesehatan masyarakat karena sering menimbulkan Kejadian Luar Biasa (KLB), berdampak 
luas terhadap kualitas hidup dan ekonomi, serta dapat mengakibatkan kematian. ${ }^{2}$

Penyakit ini masih menjadi masalah besar di beberapabagian benua afrika dan Asia. ${ }^{3}$ Oleh karena itu malaria menjadi sasaran prioritas komitmen global dalam Millenium Development Goals (MDGs) ke6 yaitu memerangi HIV/AIDS, malaria dan penyakit menular lainnya. ${ }^{4}$

Berdasarkan data dari World Health Organization(WHO) pada tahun 2013, ada 97 negara dan wilayah yang terjadi penularan malaria, dan 7 negara dalam pencegahan fase reintroduksi, sehingga total 104 negara dan wilayah yang saat ini dianggap endemik. Secara global, diperkirakan 3,4 miliar orang beresiko malaria. WHO memperkirakan bahwa 207 juta kasus malaria terjadi secara global pada tahun 2012 (ketidakpastian kisaran 135-287000000) dan 627000 kematian (ketidakpastian kisaran 473 000-789 000). Sebagian besar kasus (80\%) dan kematian (90\%) terjadi di Afrika dan sebagian besar kematian (77\%) adalah pada anak di bawah usia 5 tahun. ${ }^{5}$

Seperti kebanyakan penyakit tropis lainnya, malaria merupakan penyebab utama kematian di negara berkembang. ${ }^{3} \mathrm{Di}$ Indonesa menurut data dari Riskesdas Insiden malaria pada tahun 2013 adalah 1,9 persen menurun dibanding tahun 2007 (2,9\%), tetapi di Papua Barat mengalami peningkatan tajam jumlah penderita malaria. Prevalensi malaria tahun 2013 adalah 6,0 persen. Lima provinsi dengan insiden dan prevalensi tertinggi adalah Papua (9,8\% dan 28,6\%), Nusa Tenggara Timur (6,8\% dan 23,3\%), Papua Barat (6,7\% dan 19,4\%), Sulawesi Tengah (5,1\% dan 12,5\%), dan Maluku (3,8\% dan 10,7\%). Dari 33 provinsi di Indonesia, 15 provinsi mempunyai prevalensi malaria di atas angka nasional. ${ }^{2}$

Di Sulawesi Utara, malaria merupakan penyakit endemis karena merupakan daerah beriklim tropis sehingga rentan dengan penyakit ini. Prevalensi malaria berdasarkan Dinas Kesehatan Provinsi Sulawesi Utara pada tahun 2012 sebanyak $5,57 \%$ dengan jumlah penderita mencapai
8.691 orang, meskipun lima tahun terakhir terjadi penurunan, namun peningkatan kejadian luar biasa (KLB) masih terjadi. Beberapa daerah kabupaten/kota yang tingkat penularannya sangat tinggi, diantaranya kabupaten Sitaro, Sanger, Talaud, dan Minahasa Tenggara. ${ }^{6}$ Minahasa Tenggara merupakan kabupaten dengan jumlah kasus malaria tahun 2011 yaitu 2001 kasus dan 2005 kasus pada tahun2012. ${ }^{7}$

Penyebaran Malaria disebabkan berbagai faktor yang kompleks yaitu perubahan lingkungan, vektor, sosial budaya masyarakat, resistensi obat dan akses pelayanan kesehatan. ${ }^{8}$ Dalam upaya mengurangi angka kejadian malaria terutama di daerah endemis tinggi, upaya pencegahan dan pengobatan merupakan kunci utama. ${ }^{4}$ Salah satu yang berperan yaitu dari aspek saranan pelayanan kesehatan.

Aspek fisik dalam hal ini sarana kesehatan, perannya sangat penting dimana mampu mendukung terciptanya suatu pelayanan kesehatan yang memadai bagi masyarakat.Pelayanan kesehatan merupakan salah satu parameter untuk mengetahui status kesehatan masyarakat. Berdasarkan teori Bloom, salah satu faktor yang mempengaruhi kesehatan manusia adalah pelayanan kesehatan. Dengan kata lain berfungsinya pelayanan kesehatan dengan baik di suatu daerah mampu meningkatkan derajat kesehatan masyarakat di daerah tersebut. $^{3}$

Sarana pelayanan kesehatan yang berada di Kecamatan Silian Raya yaitu Puskesmas. Puskesmas Silian Raya merupakan puskesmas yang terletak di Desa Silian Satu, yang wilayah kerja puskesmas ini memiliki 10 desa binaan. Jumlah tenaga medis yang di miliki puskesmas ini yaitu dua dokter umum, tiga perawat dan sepuluh pembina desa yang bertugas di masing-masing desa. Berdasarkan data dari puskesmas Silian Raya Kasus malaria klinis di wilayah kerja Puskesmas Silian Raya Kabupaten Minahasa Tenggara, lewat hasil pemeriksaan parasit dalam sediaan darah 
penderita yang datang memeriksakan diri di puskesmas, angka kesakitan malaria dari bulan Januari - Oktober 2014 berjumlah 709 kasus dengan positif malaria 529 kasus. ${ }^{9}$

\section{METODE PENELITIAN}

Jenis penelitian ialah survei yang bersifat deskriptif. Penelitian ini dilakukan di Kecamatan Silian Raya Kabupaten Minahasa Tenggara, Sulawesi Utara. Populasi dalam penelitian ini ialah penduduk yang berada di Kecamatan Silian Raya, Kabupaten Minahasa Tenggara, yaitu 5731 penduduk.

Sampel pada penelitian ini ialah penduduk yang bersedia mengikuti penelitian ini. Jumlah sampel penelitian ini ditentukan berdasarkan rumus Slovin. ${ }^{10}$

$$
\begin{aligned}
& \mathrm{n}=\frac{\mathrm{N}}{1+\mathrm{N}\left(\mathrm{d}^{2}\right)} \\
& \mathrm{n}=\text { Besarnya Sampel } \\
& \mathrm{N}=\text { Besarnya Populasi } \\
& \mathrm{d}=\text { Tingkat Kepercayaan }(0,1) \\
& \mathrm{n}=\frac{5731}{1+5731(0,1)^{2}}=\frac{5731}{58,31}=98,28 \\
& \rightarrow 98
\end{aligned}
$$

Dari perhitungan rumus diatas diperoleh besar sampel sebanyak 98 penduduk di Kecamatan Silian Raya.

Pengambilan sampel penelitian menggunakan sistem Cluster Random Sampling berdasarkan penduduk pada masing-masing desa sebagai cluster. Jumlah desa di Kecamatan Silian Raya adalah 10 desa, dengan demikian dapat dihitung jumlah sampel untuk masingmasing desa sebagai berikut:

$$
\mathrm{T}=\frac{\mathrm{t}}{\mathrm{N}} \times \mathrm{n}
$$

$$
\begin{aligned}
& \mathrm{T}=\text { Jumlah Sampel pada tiap desa } \\
& \mathrm{t}=\text { Jumlah jiwa pada tiap desa } \\
& \mathrm{N}=\text { Besarnya Populasi } \\
& \mathrm{n}=\text { Besarnya Sampel }
\end{aligned}
$$

Teknik pengambilan sampel untuk setiap lingkungan menggunakan Simple Random Sampling (pengambilan sampel secara acak sederhana)

Data primer diperoleh dengan cara wawancaramenggunakan kuesioner dan observasiterhadap pelayanan kesehatan di masyarakat. Data sekunder diperoleh dari Puskesmas Silian Raya dan literatur yang relevan dengan penelitian. Teknik pengolahan data dibuat dalam sistem tabulasi menggunakan soft ware SPSS 22, kemudian dibuat dalam tabel distribusi frekwensi dan diuraikan dalam bentuk narasi.

\section{HASIL PENELITIAN}

Data pada Tabel 1 menunjukkan responden terbanyak terdapat pada kelompok usia 40 - 50 sebanyak 52 responden $(26,7 \%)$ dan responden dengan jumlah paling sedikit terdapat pada kelompok usia $<20$ tahun sebanyak 9 responden (4,6\%). Jumlah responden dalam penelitian ini sebanyak 194 responden yang diwawancarai dengan bantuan kuesioner.

Tabel 1. Distribusi responden berdasarkan kelompok usia

\begin{tabular}{ccc}
\hline $\begin{array}{c}\text { Kelompok } \\
\text { usia }\end{array}$ & Frekuensi & $\mathbf{\%}$ \\
\hline$<\mathbf{2 0}$ & 9 & 4,6 \\
$\mathbf{2 0 - 3 0}$ & 41 & 21,0 \\
$\mathbf{3 0 - 4 0}$ & 39 & 20,0 \\
$\mathbf{4 0 - 5 0}$ & 52 & 26,7 \\
$\mathbf{5 0 - 6 0}$ & 37 & 19,0 \\
$>\mathbf{6 0}$ & 16 & 8,2 \\
Total & 194 & 100,0 \\
\hline
\end{tabular}

Data Tabel 2 menunjukkan responden terbanyak berjenis kelamin perempuan 120 responden (61,9\%), responden Laki-laki sebanyak 74 reponden $(38,1 \%)$.

Data Tabel 3 menunjukkan reponden terbanyak Ibu Rumah Tangga sebanyak 100 reponden (51,5\%), dan responden dengan jumlah paling sedikit ialah pedagang sebanyak 3 responden (1,5\%). 
Tabel 2. Distribusi Responden Menurut Jenis Kelamin

\begin{tabular}{ccc}
\hline Jenis kelamin & Frekuensi & $\mathbf{\%}$ \\
\hline $\mathbf{L}$ & 74 & 38,1 \\
$\mathbf{P}$ & 120 & 61,9 \\
Total & 194 & 100,0 \\
\hline
\end{tabular}

Tabel 3. Distribusi responden menurut perkerjaan

\begin{tabular}{ccc}
\hline Pekerjaan & Frekuensi & \% \\
\hline PNS/TNI/ & 10 & 5,2 \\
POLRI & & \\
Pegawai & 0 & 0 \\
swasta & & \\
Pedagang & 3 & 1,5 \\
Nelayan & 0 & 0 \\
Petani/ & 76 & 39,2 \\
Berkebun & & \\
IRT & 100 & 51,5 \\
Wiraswasta & 5 & 2,6 \\
Total & 194 & 100,0 \\
\hline
\end{tabular}

Tabel 4. Distribusi Responden Menurut Tingkat Pendidikan

\begin{tabular}{ccc}
\hline $\begin{array}{c}\text { Tingkat } \\
\text { pendidikan }\end{array}$ & Frekuensi & $\mathbf{\%}$ \\
\hline Tidak sekolah & 2 & 1,0 \\
\hline Tidak tamat SD & 34 & 17,5 \\
SMP & 99 & 51,0 \\
SMA & 48 & 24,7 \\
Perguruan tinggi & 11 & 5,7 \\
Total & 194 & 100,0 \\
\hline
\end{tabular}

Data pada Tabel 4 menunjukkan reponden terbanyak terdapat pada tingkat pendidikan SMP sebanyak 99 reponden (51,0\%), dan reponden dengan jumlah paling sedikit terdapat pada tingkat pendidikan Tidak Sekolah sebanyak 2 responden (1,0\%).

Data pada Tabel 5 menunjukkan responden yang sudah pernah dilakukan penyemprotan tertinggi sebanyak 2 kali $39,2 \%$ dan terendah yaitu tidak pernah $6,2 \%$.

Data pada Tabel 6 menunjukkan responden yang sudah pernah dilakukan penyemprotan tertinggi sebanyak 1 kali (41,8\%) dan terendah sebanyak 3 kali $(7,2 \%)$.
Tabel 5. Distibusi responden berdasarkan pengetahuan sudah berapa kali dilakukan penyuluhan tentang pencegahan dan penanggulangan penyakit malaria

\begin{tabular}{ccc}
\hline Keterangan & Frekuensi & $\mathbf{\%}$ \\
\hline 1 Kali & 48 & 24,7 \\
2 Kali & 76 & 39,2 \\
$>$ 3 Kali & 58 & 29,9 \\
Tidak & 12 & 6,2 \\
pernah & & \\
Total & 194 & 100,0 \\
\hline
\end{tabular}

Tabel 6. Distribusi responden berdasarkan pengetahuan sudah berapa kali dilakukan penyemprotan oleh tenaga kesehatan

\begin{tabular}{ccc}
\hline Keterangan & Frekuensi & $\mathbf{\%}$ \\
\hline 1 Kali & 81 & 41,8 \\
2 Kali & 52 & 26,8 \\
> K Kali & 14 & 7,2 \\
Tidak & & \\
pernah & 47 & 24,2 \\
Total & 194 & 100,0 \\
\hline
\end{tabular}

Tabel 7. Tindakan responden jika mengalami gejala dan tanda malaria

\begin{tabular}{ccc}
\hline Keterangan & Frekuensi & $\mathbf{\%}$ \\
\hline $\begin{array}{c}\text { Membeli obat } \\
\text { warung / apotik }\end{array}$ & 14 & $7,2 \%$ \\
$\begin{array}{c}\text { Berkunjung ke } \\
\text { puskesmas }\end{array}$ & 99 & $51,0 \%$ \\
$\begin{array}{c}\text { Berobat ke } \\
\text { dokter prakter } \\
\text { swasta }\end{array}$ & 23 & $11,9 \%$ \\
$\begin{array}{c}\text { Berobat ke } \\
\text { bidan / perawat } \\
\text { desa }\end{array}$ & 58 & $29,9 \%$ \\
Total & & \\
& 194 & $\begin{array}{c}100,0 \\
\%\end{array}$ \\
\hline
\end{tabular}

Data pada Tabel 7 menunjukkan tindakan responden jika mengalami gejala dan tanda malaria tertinggi adalah Berkunjung ke Puskesmas sebanyak 99 responden $(51,0 \%)$ dan terendah yaitu membeli obat di warung/apotek 14 responden $(7,2 \%)$. 


\section{BAHASAN}

Kelompok umur dalam penelitian ini adalah 15 tahun keatas karena dianggap sudah mengerti dan mampu menjawab pertanyaan yang ada dalam kuesioner.

Untuk hasil penelitian berdasarkan jenis kelamin, responden terbanyak adalah perempuan dikarenakan pada saat pengambilan data primer yang dilakukan pada waktu siang dan sore hari, perempuan sering tinggal di rumah dan laki-laki pergi bekerja.

Hasil penelitian mengenai pekerjaan, terbanyak adalah Ibu Rumah Tangga hal ini dikarenakan pada saat pengambilan data primer, ketika dikunjungi hanya Ibu - ibu yang dapat dijumpai dirumah sedangkan bapak atau suami mereka sedang bekerja.

Distribusi responden menurut tingkat pendidikan, dalam hal ini tingkat pendidikan berhubungan dengan ketersediaan sarana pendidikan, lewat data Kabupaten Minahasa Tenggara, Kecamatan Silian Raya hanya mempunyai 4 SD dan 2 SLTP sedangkan SMA/SMK tidak tersedia. $^{11}$ Sebagaimana penelitian sebelumnya menyatakan bahwa pendidikan merupakan salah satu faktor presdisposisi yang mempengaruhi seseorang untuk membutuhkan dan mengakses pelayanan kesehatan. ${ }^{12}$

Hasil penelitian berdasarkan pengetahuan responden bahwa di tempat tinggal mereka sudah berapa kali dilakukan penyuluhan, dalam hal ini tentang pencegahan dan penanggulangan penyakit malaria, lewat penelitian Mayasari (dkk) 2012menjelaskan bahwa salah satu upaya pencegahan malaria ialah melalui peningkatan pengetahuan masyarakat melalui kegiatan penyuluhan. Dimana hasil uji statistik variabel pengetahuan dan sikap menunjukkan ada pengaruh yang signifikan antara penyuluhan dengan perubahan pengetahuan dan sikap dari masyarakat. ${ }^{12}$

Berhubungan dengan itu penelitian untuk pencarian pengobatan jika mengalami gejala malaria lewat penelitian sebelumnya menjelaskan keberhasilan pengembangan partisipasi masyarakat dalam pelaksanaan program pencegahan malaria terkait dengan ketersediaan tenaga kesehatan dan fasilitas yang digunakan dalam program pencegahan malaria, khususnya dalam pelaksanaan kegiatan penyuluhan.Peran individu masyarakat sangat ditentukan oleh kesadaran masingmasing namun bisa didororong oleh rangsangan dari luar diantaranya dengan penyuluhan. Karena kadangkala mereka tidak berbuat apa-apa karena mereka tidak tahu, sehingga perlu peningkatan pengetahuan melalui penyuluhan malaria supaya masyarakat dapat berperan serta dalam upaya penanggulangan malaria. ${ }^{12}$

Berdasarkan pengetahuan responden bahwa sudah berapa kali dilakukan penyemprotan insektisida oleh tenaga kesehatan, penyemprotan seharusnya dilakukan pada rumah dengan cakupan $>90 \%$ rumah penduduk di lokasi potensial dan di lokasi fokus malaria dengan Annual Parasite Incidence (API) $>1 \%$ yang tidak sesuai dengan penggunaan kelambu berinsektisida. ${ }^{13}$ Melalui penelitian tentang Faktor Risiko Kejadian Malaria di Kawasan Ekosistem Leuser Kabupaten Karo Provinsi Sumatera Utara menyebutkan ada pengaruh penyemprotan insektisida terhadap sarang nyamuk dengan kejadian malaria, dimana responden yang menderita penyakit malaria 4,7 kali lebih besar dengan rumah/lingkungan yang tidak dilakukan penyemprotan insektisida terhadap sarang nyamuk daripada rumah yang dilakukan penyemprotan insektisida. ${ }^{14}$

\section{SIMPULAN}

1. Peran pelayanan penyuluhan terhadap kejadian malaria di Kecamatan Silian Raya Kabupaten Minahasa Tenggara yaitu penyuluhan tentang pencegahan dan penanggulangan penyakit malaria oleh tenaga kesehatan didapatkan tertinggi 2 kali $(39,2 \%)$ dilakukan penyuluhan.

2. Peran pelayanan pencegahan dan penanggulangan kejadian malaria di Kecamatan Silian Raya Kabupaten Minahasa Tenggara yaitu penyemprotan insektisida untuk membunuh nyamuk penular malaria oleh tenaga kesehatan 
didapatkan tertinggi 1 kali (41,8\%) dilakukan penyemprotan.

3. Peran pelayanan pengobatan terhadap kejadian malaria di Kecamatan Silian Raya Kabupaten Minahasa Tenggara yaitu tindakan jika mengalami gejala dan tanda malaria, didapatkan masyarakat langsung memanfaatkan sarana pelayanan kesehatan yang tersedia yaitu Puskesmas (51,0\%).

\section{DAFTAR PUSTAKA}

1. Mangaro E. Kinerja Pemerintah Daerah Dalam Pelayanan Kesehatan Mayarakat di Kecematan Loloda Utara Kabupaten Halmahera Utara.Vol. 2, No 1.2013

2. Riset Kesehatan Dasar 2013. Badan Penelitian dan Pengembangan Kesehatan Kementerian Kesehatan RI. 2013

3. Iskandar W J, Herqutanto. Hubungan Insiden Malaria dengan Ketersediaan Unit Pelayanan Kesehatan di Kecamatan Bayah, Provinsi Banten pada Tahun 2006-2009. Program Studi Sarjana, Pendidikan Dokter Fakultas Kedokteran UI. Departemen Ilmu Kedokteran Komunitas.eJKI. 2013;1(1):37-44.

4. Laporan Pencapaian Tujuan Pembangunan Millenium di Indonesia Tahun 2011. Kementrian Perencanaan Pembangunan Nasional/ BAPPENAS. 2012

5. WHO, 2013. World Malaria Report 2013

6. Rumagit NA, Tjitrosantoso HM, Studi Penggunaan AntiMalaria pada Penderita Malaria di Instalasi Rawat Inap BLU Prof.R.D.Kandow Manado Periode Januari 2013-Mei 2013. Program Studi FMIPA UNSRAT. Pharmacon. 2013;2(3):50-3.
7. Asa $P$ E, Umboh JML, Pangemanan J. Pengaruh Penggunaan Kelambu, Repellent, Bahan Anti Nyamuk dan Kebiasaan Keluar Rumah Malam Hari Terhadap Kejadian Malaria Di Desa Lobu dan Lobu II Kecamatan Toulaan Kabupaten Minahasa Tenggara Tahun 2013. Manado: Fakultas Kesehatan Masyarakat. Universitas Sam Ratulangi, 2013.

8. Direktorat PPBB. Buku Saku Menuju Eliminasi Malaria. Jakarta, April 2011.

9. Puskesmas Kecamatan Silian Raya. Profil Puskesmas Kecamatan Silian Raya Tahun 2014.

10. Setiawan N. Penentuan ukuran sampel memakai rumus slovin dan tabel Krejcie-Morgan. Telaah konsep dan aplikasinya (Diskusi ilmiah). Bandung: Fakultas Peternakan Universitas Padjajaran, 2007.

11. Kabupaten Minahasa Tenggara. Data Umum Kabupaten Minahasa Tenggara Tahun 2012.

12. Mayasari R, Sitorus H, Ambrita LP. Dampak Penyuluhan Terhadap Peningkatan Pengetahuan, Sikap \& Perilaku Masyarakat Tentang Malaria di Desa Sukajadi Kabupaten Oku. Jurnal Pembangunan Manusia. 2012;6(3).

13. Permenkes RI. Rekam Medis . No.269/Menkes/Per/III/2008 [cited 2014, Sep 25]. Available from: http://apikes.wordpress.com/category/re kam-medis/

14. Sarumpet SM, Tarigan R. Faktor Risiko Kejadian Malaria di Kawasan Ekosistem Leuser Kabupaten Karo Provinsi Sumatera Utara. Fakultas Kesehatan Masyarakat. Universitas Sumatera Utara. 2006. 